\title{
Pyroxene structures, cathodoluminescence and the thermal history of the enstatite chondrites
}

\author{
Yanhong Zhang ${ }^{\prime *}$, Shaoxiong Huang ${ }^{1}$, Diann Schneider', Paul H. Benoit', \\ John M. DEHART ${ }^{2,3}$, GARY E. LOFGREN ${ }^{3}$ AND DEREK W. G. SEARS \\ 'Cosmochemistry Group, Department of Chemistry and Biochemistry, University of Arkansas, Fayetteville, Arkansas 72701, USA \\ ${ }^{2}$ Energy Laboratories, Inc., Casper, Wyoming 82601, USA \\ ${ }^{3}$ SN4, NASA Johnson Space Center, Houston, Texas 77058, USA \\ *Correspondence author's e-mail address: ychang@uafsysb.uark.edu
}

(Received 1995 May 30; accepted in revised form 1995 October 17)

\begin{abstract}
In order to explore the thermal history of enstatite chondrites, we examined the cathodoluminescence (CL) and thermoluminescence (TL) properties of $15 \mathrm{EH}$ chondrites and $21 \mathrm{EL}$ chondrites, including all available petrographic types, both textural types 3-6 and mineralogical types $\alpha-\delta$. The CL properties of EL $3 \alpha$ and $\mathrm{EH} 3 \alpha$ chondrites are similar. Enstatite grains high in $\mathrm{Mn}$ and other transition metals display red $\mathrm{CL}$, while enstatite with low concentrations of these elements show blue $\mathrm{CL}$. A few enstatite grains with $>5 \mathrm{wt} \% \mathrm{FeO}$ display no $\mathrm{CL}$. In contrast, the luminescent properties of the metamorphosed $\mathrm{EH}$ chondrites are very different from those of metamorphosed EL chondrites. While the enstatites in metamorphosed EH chondrites display predominantly blue $\mathrm{CL}$, the enstatites in metamorphosed EL chondrites display a distinctive magenta $\mathrm{CL}$ with blue and red peaks of approximately equal intensity in their spectra. The TL sensitivities of the enstatite chondrites correlate with the intensity of the blue CL and, unlike other meteorite classes, are not simply related to metamorphism. The different luminescent properties of metamorphosed EH and EL chondrites cannot readily be attributed to compositional differences. But x-ray diffraction data suggests that the enstatite in $\mathrm{EH} 5 \gamma, \delta$ chondrites is predominantly disordered orthopyroxene, while enstatite in EL6 $\beta$ chondrites is predominantly ordered orthopyroxene. The difference in thermal history of metamorphosed EL and EH chondrites is so marked that the use of single "petrographic" types is misleading, and separate textural and mineralogical types are preferable. Our data confirm earlier suggestions that metamorphosed EH chondrites underwent relatively rapid cooling, and the metamorphosed EL chondrites cooled more slowly and experienced prolonged heating in the orthopyroxene field.
\end{abstract}

\section{INTRODUCTION}

Enstatite chondrites were formed in a very reducing environment and contain essentially FeO-free enstatite, high-Si metal and the cubic monosulfides, such as niningerite and alabandite (Keil, 1968; Mason 1966). While essentially chondritic in bulk composition, variations in $\mathrm{Fe} / \mathrm{Si}, \mathrm{Mg} / \mathrm{Si}$ and similar ratios enable the definition of discrete $\mathrm{EH}$ (high-Fe, high-siderophile) and EL (low-Fe, low-siderophile) classes (Sears et al, 1982). The enstatite chondrites also have especially interesting thermal histories. Several authors have used equilibria for enstatite, metal and other phases to estimate equilibration temperatures, which seem reasonable in terms of the observed textures and the petrographic types (Larimer and Buseck, 1968; Fogel et al., 1989; Zhang et al., 1992). However, equilibration temperatures (more precisely, closure temperatures) based on minor mineral systems are very different from those based on the major phases and are higher for the $\mathrm{EH}$ chondrites than for the EL chondrites. For the cubic sulfides, equilibration temperatures are $<400{ }^{\circ} \mathrm{C}$ for the $\mathrm{EL}$ and $\sim 600{ }^{\circ} \mathrm{C}$ for the $\mathrm{EH}$ chondrites (Skinner and Luce, 1971; Zhang et al., 1992). The usual interpretation is that $\mathrm{EH}$ chondrites cooled more rapidly than $\mathrm{EL}$ chondrites. The dichotomy between texture and equilibration temperatures determined from the sulfide and phosphide systems led Zhang et al. (1995) to argue that the Van Schmus and Wood (1967) scheme, which works well for ordinary chondrites, is not well-suited to enstatite chondrites. They proposed separate mineralogical and petrographic "types" for these classes. Thus, while the textural types 3-6 reflect peak metamorphic temperatures and are similar for $\mathrm{H}$ and $\mathrm{L}$ chondrites, mineralogical types $\alpha-\delta$ reflect mineralogical closure temperatures and are quite different for $\mathrm{H}$ and $\mathrm{L}$ chondrites.

There has always been a high degree of interest in the cathodoluminescence (CL) properties of the enstatite chondrites and the related igneous class, the aubrites. This interest is partly because the CL intensity is so high but also because variations in trace-element compositions cause major differences in CL properties (Derham and Geake, 1964; Derham et al., 1964; Geake and Walker, 1966, 1967; Reid and Cohen, 1967; Grögler and Liener, 1968; Keil, 1968; Leitch and Smith, 1982; McKinley et al., 1984; Stecle, 1989; Lofgren and DeHart, 1992a,b, 1993; DeHart and Lofgren, 1994, 1995; Weisberg et al., 1994). The luminescent properties of enstatite have been reviewed several times (e.g., Marshall, 1988; Steele, 1989). Enstatite grains with red CL $(\sim 700$ $\mathrm{nm}$ ) have high concentrations of transition metal activators, such as $\mathrm{Cr}$ and $\mathrm{Mn}$, while enstatite with blue $\mathrm{CL}(\sim 450 \mathrm{~nm})$ is relatively pure $\mathrm{MgSiO}_{3}$. While the dependence of $\mathrm{CL}$ on composition is well established, an important proposal by Reid and Cohen (1967) that has not been discussed very much in the literature is that the degree of stacking disorder of the enstatite also affects its CL.

While it is recognized that $\mathrm{CL}$ offers particular insights into the origin and history of the host rocks, most of the studies of enstatite chondrites to date have concerned only single or small groups of meteorites with attention focused on individual grains and their compositional profiles. The discovery of a great many enstatite chondrites among the Antarctic collection in the last decade or so (Cassidy et al., 1992), including many in previously unoccupied positions in the chemical-petrologic grid (e.g., the EL3 chondrites described by Lin et al., 1991, and Chang et al., 1992), means that 
this is an opportune time to examine the luminescent properties of enstatite meteorites as a class. We obtained a suite of $\mathrm{EH}$ and $\mathrm{EL}$ chondrites, covering the available spectrum of textural and mineralogical types, and made photographic mosaics of the CL of entire thin sections. We discovered trends not previously recognized that we suggest are the result of differences in the thermal history of the $\mathrm{EH}$ and EL classes. To help interpret these trends, we performed $\mathrm{x}$ ray diffraction measurements.

The thermoluminescence (TL) process usually involves the same luminescent centers as CL, and the two techniques are closely related, although our TL apparatus is equipped with filters to restrict black-body radiation that results in a bias towards blue light. Because metamorphic history is a particularly important aspect of enstatite chondrite history and since induced TI, measurements have proved useful in exploring the metamorphic history of ordinary and carbonaceous chondrites (Sears et al, 1980, 1991a,b; Guimon et al., 1995), we included induced TL measurements in the present study.

\section{EXPERIMENTAL}

\section{Samples Studied}

The samples that were obtained are listed in Table 1. Descriptions can be found in Keil (1968) and Zhang et at. (1995). The samples included representative EH and EL chondrites of all available textural types 3-6 and mineralogical types $a-\delta$. LEW88180 was classified as an EH6 by Mason (1990) while Zhang et al. (1995) described it as EHS8. T11.91714 is the second known EI.5; RKPA80259 was the first. Both metcorites have the CL. properties of EI.6 chondrites, which are quite unlike those of EH5 chondrites (Zhang et al., 1994a). There can no longer be any uncertainty as to the classification of RKPA80259 (Weeks and Sears, 1985; Kallemeyn and Wasson, 1986); it is clearly an ELS chondrite

\section{Cathodoluminescence}

Cathodoluminescence mosaics were prepared from 10-20 photographs using polished thin sections, typically $1 \mathrm{~cm} \times 1.5 \mathrm{~cm}$, of 23 enstatite chondrites. A commercial Nuclide Instruments "Luminoscope" attached to a low-magnification optical microscope was operated at $13 \pm 1 \mathrm{kV}$ and $8 \pm$ $1 \mathrm{~mA}$ and the images photographed with Kodak "Gold" $400 \mathrm{film}$. exposed for $20 \mathrm{~s}$ to $40 \mathrm{~s}$. Equilibrated EH chondrites typically required $\sim 10 \mathrm{~s}$ longer

TABLE 1. Calhodoluminescence and related properties of enstatite chondrites. ${ }^{*}$

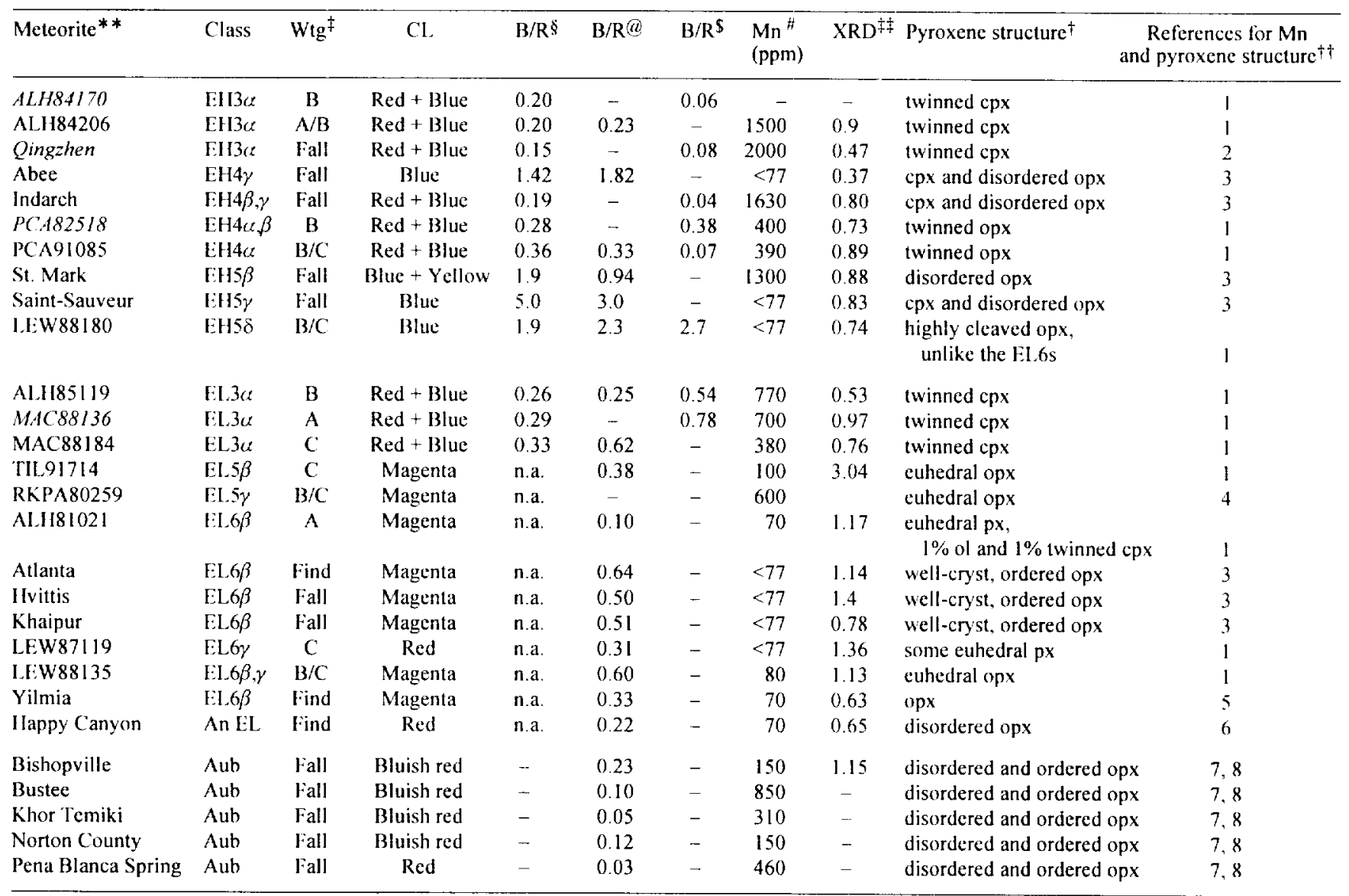

* Meteorites listed alphabetically within class, mineralogical $(\alpha-\delta)$ and textural $(3-6)$ type. See Zhang et al. (1995) for details $-=$ data not available.

** Cathodoluminescence data for meteorites in italics were obtained by JMD at the Johnson Space Center; $A u b r i t e$ data from Geake and Walker (1966).

‡ Weathering category as defined by Score and Lindstrom (1990).

$\$$ Ratio of the blue C.L to red C.I. as determined by point-counting the cathodoluminescence images. n.a. indicates that this parameter is not applicable to these samples.

(6) The intensity of the $450 \mathrm{~nm}$ to $700 \mathrm{~nm} \mathrm{Cl}$, (aubrite data from (jeake and Walker, 1966).

$\$$ Data from DeHart and Lofgren (1995).

\# Mn contents of the enstatite were obtained without regard to $\mathrm{CL}$ and are thus weighted averages of grains with blue and red $\mathrm{CL}$. Typically, in unmetamorphosed (type $3 a$ ) enstatite chondrites, red grains contain $-2000 \mathrm{ppm}$ Mn while in blue CL grains the Mn is below detection limits. the ratio of the intensity of the (420), (221) doublet and $(610)$ peak in the X-ray diffraction pattern, see Pollack and Ruble (1964).

$\dagger$ "cpx," "opx" and "ol" refer to clinopyroxene, orthopyroxene and olivine, respectively.

t† References as follows: 1. Zhang et al (1995); 2. Wang and Xie (1981); 3. Keil (1968); 4. Sears and Weeks (1984); 5. Buseck and Ioldsworth (1972); 6. Olsen ef al. (1977); 7. Watters and Prinz (1979); 8. Pollack (1966). 
than equilibrated LI, chondrites. The film was developed with the C-4I process. Some of the present mosaics were obtained at the Johnson Space Center using the same lechniques. Aubrite data were taken from the literature.

Spectra were obtained from the $\mathrm{Cl}$. negatives using a UV-visible spectrometer (IIP8452). Three arcas each of $-0.2 \mathrm{~cm} \times 1 \mathrm{~cm}$ were scanned; backgrounds measured using blank portions of the same negatives were subtracted; and the spectra were averaged. The data were then converted from absorbancies to reflectivities for comparison with the $\mathrm{Cl}$ prints. Repeated measurements on blank portions of film processed over a twoyear period showed remarkable constancy in film response. The spectra obtained agree very well with those of individual grains obtained by direct spectrometry by Geake and Walker (1966). We tried to determine a quantitative relative estimate of the blue and red grains by point-counting the CI mosaics and by taking the ratios of the heights of the red $(-700 \mathrm{~mm})$ and blue $(\sim 450 \mathrm{~nm})$ peaks in the ( 1 , spectra. On occasion, the blue peak did not reach a maximum before the instrumental cut-off and the value at $450 \mathrm{~nm}$ was taken. These two methods of data reduction are insensitive to exposure times because they are both essentially "internally calibrated."

\section{Optical Microscopy, Electron-Microprobe Analysis and $\mathrm{X}$-ray Diffraction}

The thin sections were cxamined under the optical microscope and observations on the nature of the pyroxene are reported in Table 1 Finstatite compositions for 12 samples were determined using the Cameca electron microprobe at the Jolnnson Space Center, Houston. The accelerating voltage was $15 \mathrm{kV}$ with a heam diameter of $1 \mathrm{um}$ and beam current of $17 \mathrm{nA}$. Data for live to ten grains were normally averaged for each meteorite, kacrsutite $\left[\left(\mathrm{Ca}_{2}(\mathrm{Na}, \mathrm{K})\left(\mathrm{Mg}, \mathrm{Fe}_{4} \mathrm{TiSi}_{6} \mathrm{Al}_{2} \mathrm{O}_{2} \mathrm{~F}_{2}\right]\right.\right.$ was used as a standard for $\mathrm{Ca}$, Ii, $\mathrm{Fe}, \mathrm{Si}$ and $\mathrm{Mg}$ and garnet for $\mathrm{Mn}$. Complete analyses are reported in thang et al. (1995).

The $x$-ray diffraction patterns over the $26^{\circ}$ to $38^{\circ} 2 \theta$ range were obtained for $20 \mathrm{mg}$ nonmagnetic powder using a Philips diffractometer with a scanning rate of $2 \%$ min and (u $\mathrm{K} \alpha$ radiation. The relative heights of the (420), (221) doublet and the (610) peak were used as an order/disorder parameter in the way described by Pollack and Ruble (1964). These authors pointed out that for ordered orthopyroxene the doublet was usually more intense than the singlet, while the reverse was truc for disordered orthopyroxene. To test our methods and evaluate precision, we prepared

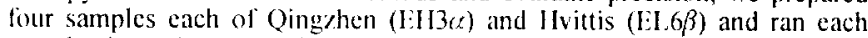
sample three times, making sure that different parts of the powder were scanned each time. The ratios of the peak heights of the doublet to that of the singlet are shown in Fig. I. The precision obtained in this experiment is comparable to the standard deviation of the mean peak height ratios for I:Il and EL, chondrites ( Table I) and is $-30 \%$ of the value measured.

\section{Induced Thermoluminescence}

We performed Tl, measurements on 14 lill chondrites and 20 I:I. chondrites of textural types $3-6$ and mineralogical type $(t-\delta$ (Table 2), the samples were those used in the recent study of bulk and mineral compositions by Zlong et al $(1993,1995)$. The apparatus and procedures were those of Sears et al. (1991a). Dhajala was used as a normalization standard and long-term stability check for the apparatus. All operations were performed in temperature- and humidity-controlled laboratories and under red light; the T1 measurements were made with Daybreak Nuclear and Medical apparatus fitted with thermal and blue filters and a heating rate of $7.5^{\circ} \mathrm{C} / \mathrm{s}$. After draining the natural $\mathrm{Tl}$, by heating to $500^{\circ} \mathrm{C}$, the samples were exposed to a $250 \mathrm{mC} ;{ }^{\circ} \mathrm{Sr}$ beta-ray source and the induced $\mathrm{TL}$ measured. Three $4 \mathrm{mg}$ aliquots of nonmagnetic, homogenized 100-mesh powder were used for the Tl measurements, and three aliquots were analyzed for each sample. Some variation in TI. sensitivity is possibly the result of weathering, but acid-washing experiments as described by Benoit et al (1991) indicate that this is of minor importance for the present samples.

\section{RESULTS}

\section{Cathodoluminescence}

The CL Images of EH Chondrites-Photographs of representative CI, mosaics are shown in Plate la-d. Enstatite grains with red or blue Cl, and rare areas of chondrule mesostasis with yellow $\mathrm{Cl}$, are observed in both $1: H 3 a$ and EI I 4 ch chondrites. Very occasionally, we observed isolated grains with yellow CL, that might be Cas, but weathering would have destroyed this mineral in most of our

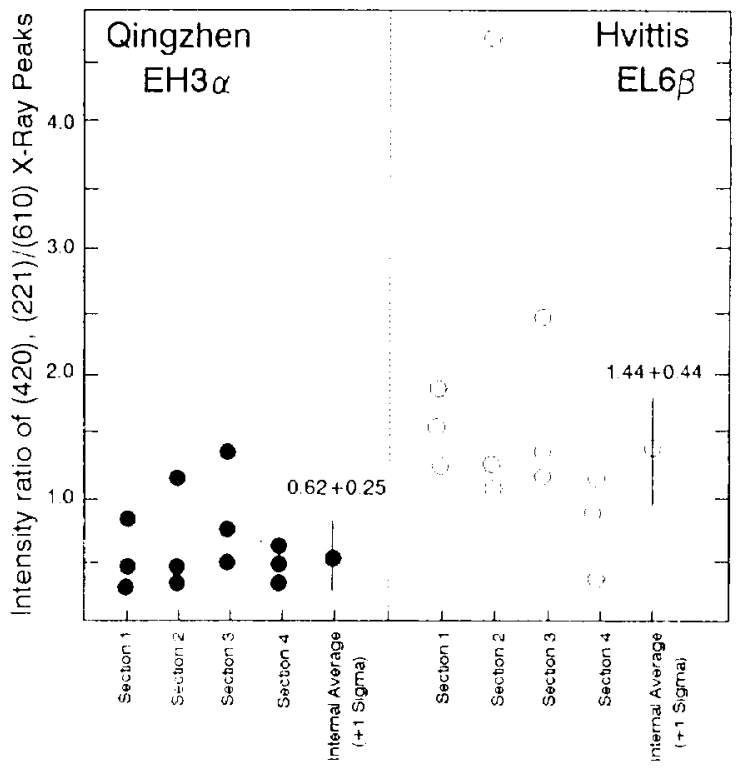

FIG. 1. Plots of the ratio of the 420,221 doublet to the 610 singlet in the $x$ ray diffraction pattern of two enstatite chondrites. Four sections of each sample were prepared, and each was scanned three times. According to Pollack and Ruble (1964), the doublet is more intense than the singlet for ordered enstatites while the reverse is true of disordered enstitite. The internal average (average ignoring the highest and lowest points) is shown for the peak height ratios of each meteorite.

samples. A few grains displaying no $\mathrm{Cl}$ are rare enstatites with $>5$ wt\% FeO (Lusby et al., 1987; Weisherg et al., 1994). Enstatite with almost pure blue $\mathrm{CL}$ was the major luminescent phase in the SaintSauveur (EH5y) chondrite. However, in the LEW88180 (EI158) and $\mathrm{Abee}(\mathrm{EH} 4 \gamma$ ) chondrites, $-90 \%$ of the enstatite displays blue $\mathrm{Cl}$. and the remainder shows magenta $\mathrm{Cl}$. While in St. Marks $(\mathrm{EH} 5 \beta)$, $\sim 90 \%$ of the enstatite displays blue $\mathrm{CL}$, and the remainder is yellow $\mathrm{CL}$, which is characteristic of chondrule mesostasis.

The CL Images of El Chondrites-The EL $3 \alpha$ chondrites resemble the $1: H 3 z$ chondrites in their $\mathrm{Cl}$. properties, containing mostly enstatite with red CL but occasionally grains with blue $\mathrm{CL}$, or no C.L are found (Plate la-h). There are very rare chondrules whose mesostases produce yellow CL. (Plate $1 \mathrm{e}-1 \mathrm{l}$ ). The enstatite grains in the EL5 $\beta$ and EL6 $\beta$ chondrites display a magenta $C 1$ with irregular and interdigitated regions whose $C L$ appears to be brown.

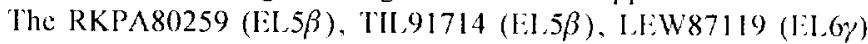
and anomalous Happy Canyon I:L-related chondrite also display magenta CL.

The CL Spectra-Some representative spectra are shown in Fig. 2. The spectra for a given meteorite are highly reproducible, especially for the higher petrographic types, with peaks at $-450 \mathrm{~nm}$ and $\sim 700 \mathrm{~nm}$. Quantitative data, extracted from the spectra, are shown in Fig. 3. The relative abundance of red and blue grains, determined by point counting the CL photographs, agrees well with peak height ratios determined from spectra (Table 1). In general, EL, chondrites have stronger blue and red CL intensity than Ell chondrites. The metamorphosed EH chondrites are noteworthy for their high blueto-red $\mathrm{Cl}$, ratios. For the III series, the intensity of the blue $\mathrm{Cl}$. increases with textural and mineralogical types. For the EL chondrites, the CL intensity and blue-10-red ratio are independent of types 
The X-ray Diffraction, Optical Microscopy and Electron Microprobe Data

Observations based on optical microscopy, $x$-ray diffraction and electron microprobe analysis are listed in Table 1 and shown in Fig. 4. The intensity of the (420), (221) doublet in the $x$-ray diffraction patterns is less than the intensity of the (610) peak for the EH chondrites and the EL $3 \alpha$ chondrites analyzed, which is indicative of disordered orthopyroxene. The $x$-ray diffraction data for the EL6 $\beta$ chondrites are fairly heterogeneous, but for eight of twelve samples the doublet is stronger than the singlet, indicating the presence of ordered orthopyroxene. Only for Khairpur and Yilmia is the doublet weaker than the singlet. Both EH $3 \alpha$ and EL3 $\alpha$ chondrites contain mainly twinned-clinopyroxene, in a variety of grain sizes,

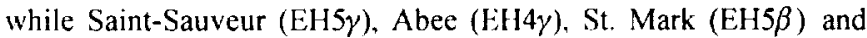
LEW 88180 (EH6ס) contain disordered orthopyroxene (Table 1). The EL6 $\beta$ chondrites contain euhedral pyroxene without cleavage planes, which is generally ordered orthopyroxene. The $\mathrm{Mn}$ content of the enstatite generally decreases with increasing textural type for both $\mathrm{EH}$ and $\mathrm{EL}$ chondrites and is below the detection limit in textural types 5 and 6 .

\section{Thermoluminescence}

The $\mathrm{EH}$ and $\mathrm{EL}$ chondrites display $\mathrm{TL}$ peaks at $\sim 140^{\circ} \mathrm{C}$ and $\sim 300^{\circ} \mathrm{C}$. However, the $\sim 140^{\circ} \mathrm{C}$ peak can sometimes be resolved into separate peaks at $125^{\circ} \mathrm{C}$ and $175^{\circ} \mathrm{C}$ and the $-300^{\circ} \mathrm{C}$ peak may show peaks at $280^{\circ} \mathrm{C}$ and $330^{\circ} \mathrm{C}$ (Fig. 5). The $\mathrm{EH} 3 \alpha$ chondrites are missing the higher temperature peak. Figure 6 shows the TI. sensitivities. The high temperature peak for the EL $6 \beta$ chondrites shows considerable scatter, which might be related to the scatter in the $\mathrm{x}$-ray diffraction data. The EL chondrites show a much larger range than the $\mathrm{EH}$ chondrites and extend to higher $\mathrm{TL}$, sensitivities by factors of $\sim 4$. Both TL peaks show a small increase in TL sensitivity with petrographic type within the $\mathrm{EH}$ chondrites with values going from $<0.01$ to 0.2 (Dhajala $=1$ ) However, there is no systematic trend in TL sensitivity with petrographic type among the $\mathrm{EL}$ chondrites. Instead, both TL peaks range from $<0.05$ to 0.6 for the EL $3 \alpha \alpha$ chondrites and from $<0.01$ to 0.9 for the EL6 $\beta$ chondrites (Zhang et al., 1994b).

\section{DISCUSSION \\ Composition, Structure and $C L$ of the Pyroxene in Enstatite Chondrites}

$\begin{array}{lllll}\text { Qingzhen } & \mathrm{EH} 3 \alpha & \text { Fall } & 134 \pm 8 & 0.183 \pm 0.008\end{array}$

MAC 88136

$116 \pm 2 \quad 0.480 \pm 0.050$

$\begin{array}{lllll}\mathrm{EET} T 3322 & \mathrm{EH} 3 \alpha & \mathrm{A} / \mathrm{B} & 138 \pm 15 & 0.042 \pm 0.00\end{array}$

$\begin{array}{lllll}\text { EET87746 } & \text { EH } 4 \alpha \beta & C & 135 \pm 7 & 0.071 \pm 0.007\end{array}$

Kota-Kota

Abee $^{+}$

$\mathrm{EH} 3 \alpha$ Find

$0.183 \pm 0.008$

$\begin{array}{lll}\text { EH } 4 \gamma \quad \text { Fall } & 121 \pm 5 & 0.122 \pm 0.010\end{array}$

Adhi-Kot

Indarch

EH $4 \gamma$ Fall

EH $4 \beta, \gamma \quad$ Fall $\quad 142 \pm 11 \quad 0.042 \pm 0.004$

PCA82518

PCA91085

PCA91238

St. Marks ${ }^{+}$

$\mathrm{EH} 4 \alpha \beta \quad \mathrm{B}$

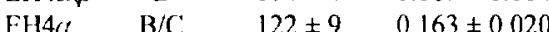

$\begin{array}{llll}\text { EH } 4 \alpha & \text { B } & 169 \pm 26 & 0.046 \pm 0.006\end{array}$

$\begin{array}{llll}\text { EH5 } \beta \quad \text { Fall } & 121 \pm 3 & 0.230 \pm 0.030\end{array}$

L.EW $88180^{+}$

EH5

$\mathrm{B} / \mathrm{C}$

$111 \pm 5$

$0.086 \pm 0.006$

$126 \pm 6 \quad 0.285 \pm 0.022$

$119 \pm 6 \quad 0.223 \pm 0.020$

$146 \pm 6 \quad 0.142 \pm 0.020$

EET90299

EL3 $a$

B

EL $3 a$

EL3 $3 a$

MAC88184

PCA91020 $0^{+}$

TIL91714

ALH81021

Atlanta

Daniel's Kuil

Eagle

EET90102

Hvittis

Khairpur

LEW87I19

LEW88135

LEW88714

Pillistfer

Yilmia

Happy Canyon
EL3 $a$

EL3 $\beta$

EL5 $\beta$

EL6 $\beta$

EL6 $\beta$

EL6 $\beta$

$147 \pm 10 \quad 0.540 \pm 0.046$

$124 \pm 7 \quad 0.087 \pm 0.008$

$115 \pm 8 \quad 0.434 \pm 0.028$

$145 \pm 10 \quad 0.307 \pm 0.013$

$131 \pm 17 \quad 0.300 \pm 0.060$

$119 \pm 3 \quad 0.899 \pm 0.178$

$130 \pm 10 \quad 0.330 \pm 0.030$

$\begin{array}{llll}\text { EL6 } & \text { B } / C & 147 \pm 14 & 0.220 \pm 0.024 \\ \text { EL6 } \beta & \text { Fall } & 136 \pm 9 & 0.604 \pm 0.027\end{array}$

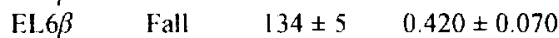

$\begin{array}{llll}\text { EL6 } & C & 124 \pm 6 & 0.108 \pm 0.013\end{array}$

$\begin{array}{llll}E L 6 \beta, \gamma & B / C & 141 \pm 6 & 0.069 \pm 0004\end{array}$

$\begin{array}{llll}\text { FL } 6 y & C & 130 \pm 8 & 0.142 \pm 0.010\end{array}$

$\begin{array}{llll}\text { EL6 } \beta & \text { Fall } & 122 \pm 14 & 0.430 \pm 0.049\end{array}$

$\begin{array}{lll}\text { EL6 } \beta \text { Find } 134 \pm 5 & 0.088 \pm 0.009\end{array}$

$175 \pm 4 \quad 0.200 \pm 0.030$
Peak 2

$\left({ }^{\circ} \mathrm{C}\right) \quad($ Dhajala $=1)$

$\begin{array}{ll}- & - \\ - & - \\ - & -\end{array}$

$-$

$312 \pm 3$

$313 \pm 21$

$293 \pm 5$

$313 \pm 6$

$309 \pm 1$

$291 \pm 8$

$315 \pm 17$

$311 \pm 3$

$294 \pm 9$

$304 \pm 4$

$311 \pm 10$

$300 \pm 8$

$302 \pm 2$

$288 \pm 7$

$310 \pm 16$

$263 \pm 13$

$340 \pm 0$

$282 \pm 20$

$317 \pm 11$

$281 \pm 10$

$236 \pm 12$

$324 \pm 14$

$347 \pm 7$

$280 \pm 12$

$331 \pm 2$

$333 \pm 6$

$287 \pm 3$
$0.017 \pm 0.003$

$0.073 \pm 0.007$

$0.115 \pm 0.021$

$0.024 \pm 0.003$

$0.141 \pm 0.029$

$0.050 \pm 0.006$

$0.137 \pm 0.040$

$0.150 \pm 0.020$

$0.052 \pm 0.008$

$0.145 \pm 0.023$

$0.190 \pm 0.015$

$0.126 \pm 0.016$

$0.460 \pm 0.040$

$0.080 \pm 0.010$

$0.523 \pm 0.060$

$0.171 \pm 0.012$

$0.280 \pm 0.030$

$0.130 \pm 0.020$

$0.485 \pm 0.100$

$0.140 \pm 0.010$

$0.460 \pm 0.009$

$0.250 \pm 0.040$

$0.041 \pm 0.007$

$0.024 \pm 0.004$

$0.047 \pm 0.004$

$0.250 \pm 0.028$

$0.043 \pm 0.003$

$0.140 \pm 0.020$

\footnotetext{
* Meteorites listed alphabetically within class, mineralogical $(\alpha-\delta)$ and textural (3-6) type. See Zhang et al. (1995) for details. Uncertainties are standard deviations based on triplicate measurements of aliquots from a single homogenized powder. $-=$ peak absent.

Weathering category as defined by Score and Lindstrom (1990).

+ These meteorites have resolvable peaks at intermediate temperatures. The temperatures and $\mathrm{TI}$. sensitivities of these peaks are: Abee $=196 \pm 5,0.085 \pm 0.010$; St. Marks $=181 \pm 2,0.200 \pm 0.030$; LEW88180 = $170 \pm 5,0.074 \pm 0.008 ; P C A 91020=176 \pm 14,0.385 \pm 0.030$, respectively.

F An = anomalous; see 7 hang et al (1995) for details.
}

$268 \pm 6$
Compositional Factors-Iron and several minor and trace elements in enstatite underwent reduction or diffusive equilibration with other phases during metamorphism and fell to values near or below their detection limits (Keil, 1968; Table 1). A great many studies of the $C L$ and composition of enstatite and profiles within individual grains have shown that high transition element abundances favor red CL while grains low in these elements have blue CL (Reid and Cohen. 1967; Leitch and Smith, 1982; McKinley et al, 1984; Steele, 1989; Lofgren and DeHart, 1992a,b, 1993; DeHart and Lofgren, 1994; Weisberg et al, 1994). It, therefore, seems reasonable to predict that the $\mathrm{CL}$ properties of enstatite chondrites would become progressively dominated by blue CL grains with increasing metamorphism. While blue $\mathrm{Cl}$, is associated with low trace-element content, the mechanism producing the $\mathrm{Cl}$, is unclear. The blue $\mathrm{CL}$ of $\alpha$ quartz (450 nm) is thought to be an intrinsic property of the $\mathrm{SiO}_{4}$ tetrahedron and not due to activation by impurity ions (Waychunas, 1988). The ubiquitousness of the blue $\mathrm{CL}$ in silicates is consistent with this idea although not proof (Steele, 1989). As expected, the EH chondrites show a trend of decreasing $\mathrm{Mn}$ with increasing blue/red ratio (Fig. 7). However, the equilibrated EL chondrites, while containing enstatite with low $\mathrm{Mn}$ and other trace and minor elements that are similar to those of the equilibrated EH 

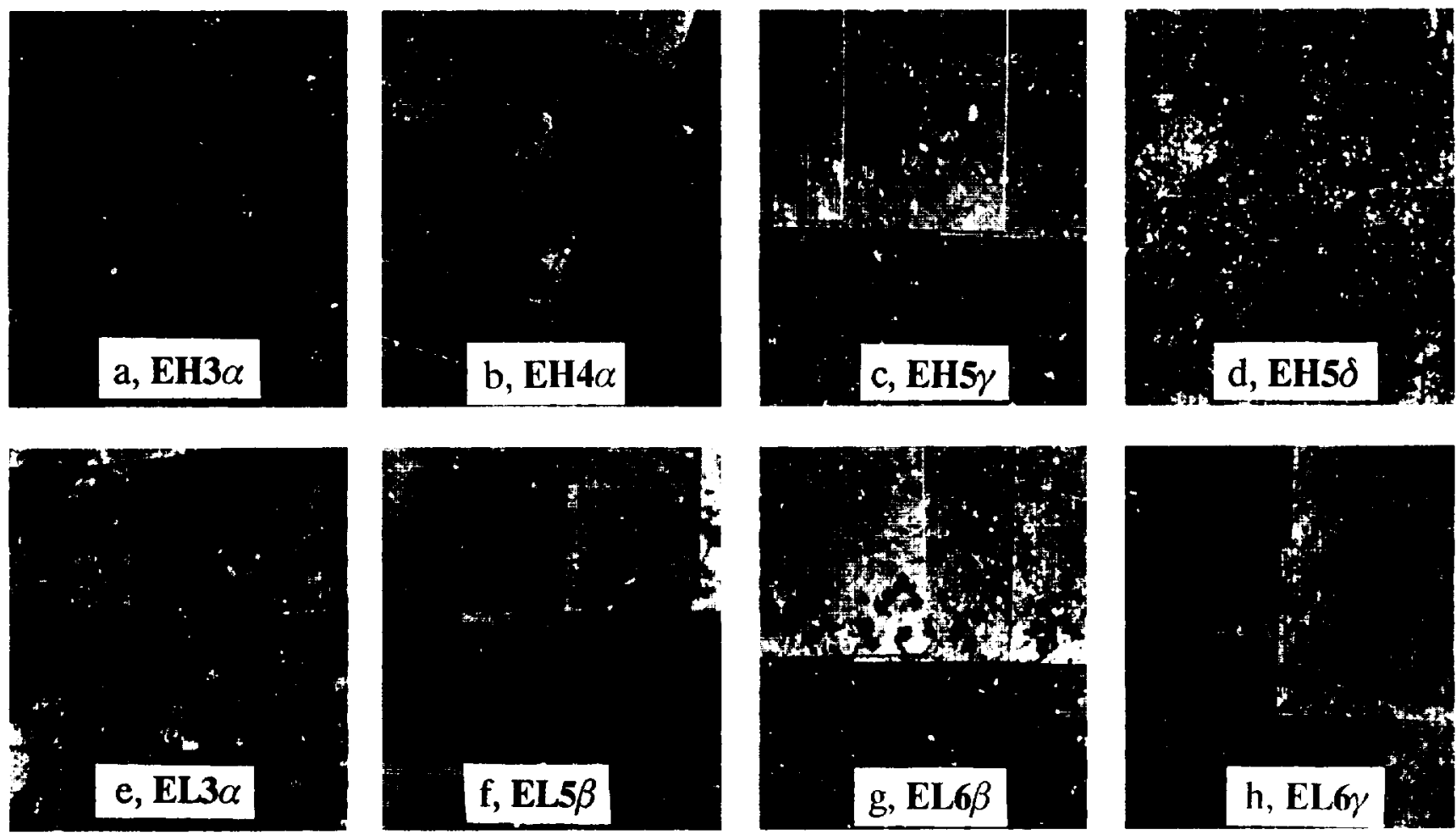

PLATE: 1. Mosaics of the cathodoluminescsence of EH chondrites (upper series) and EL chondrites (lower series) in order of increasing petrographic type (a) ALI184206, (b) PCA91085 (paired with PCA82518), (c) Saint Sauveur, (d) LEW88180, (c) ALH85119, (f) TII 91714, (g) AL.11A81021 and (h) LEW87119. The EI13 $a$, FL $3 \&$ and EH4 4 chondrites (there are no known EL4 chondrites) display predominantly red CL with occasional grains of blue or no $\mathrm{Cl}$. For the EII chondrites of higher petrologic type, the $\mathrm{CL}$ is predominantly blue with relatively few grains exhibiting magenta $\mathrm{Cl}$. The equilibrated EL chondrites have enstatite with almost entirely magenta $\mathrm{Cl}$ and a few obscure well-integrated regions of brownish $\mathrm{CL}$. The horizontal field of vicw in all images is $-0.5 \mathrm{~cm}$

chondrites, display a large range in $\mathrm{Cl}$. intensity and blue to red ratio, which is unrelated to the composition of the enstatite (Fig. 7). It should be mentioned that while we discuss $\mathrm{Mn}$, which is widely associated with the red $\mathrm{CI}$ of enstatite, other transition metal impurity ions are strongly correlated with $\mathrm{Mn}$ in enstatite, and the same arguments apply if they are activators. Properties besides trace-clement abundances determine the $\mathrm{Cl}$ properties of the enstatite in these meteorites.

Structural Factors-Enstatite exists as orthoenstatite, lowclinoenstatite, high-clinoenstatite and protoenstatite, but the detailed phase relations are unclear (e.g., Brown and Smith, 1963; Mason, 1968; Smyth, 1974; Pacalo and Gasparik, 1990; Kanzaki, 1991; Angel et al. 1992). Clinopyroxene occurs in low textural types of enstatite chondrites, while orthopyroxene occurs in the high types (Mason, 1968; Keil, 1968). Isolated descriptions of ordered and disordered orthopyroxene in enstatite chondrites and aubrites have been reported by many authors (Keil, 1968; Reid et al., 1964; Reid and Cohen, 1967), but no systematic variation with class or type has been reported. At low pressures, protoenstatite is the stable form of $\mathrm{MgSiO}$ between $1000^{\circ} \mathrm{C}$ and $1300^{\circ} \mathrm{C}$ (Smyth 1974). Orthoenstatite and low-temperature clinoenstatite are the common forms in meteorites since high-clinoenstatite is stable only at pressures $>7$ GPa. The phase boundary between orthoenstatite and low-clinoenstatite is indistinct, largely because of the slow kinetics of the transformation. so that it is possible for enstatite to occur as a mixture of orthoenstatite and low-clinoenstatite (Buseck et al, 1982).
The co-existence of two polymorphs in individual enstatite grains is sometimes referred to as stacking disorder and is distinct from cation disordering (e.g., Skogby, 1992). Stacking disorder in orthopyroxene is readily detected by the single crystal Weissenberg method because it produces both sharp and difluse spots (Pollack, 1968). It has been suggested that fast cooling of protopyroxene from $1000{ }^{\circ} \mathrm{C}$ to $700{ }^{\circ} \mathrm{C}$ produces disordered pyroxenc sometimes with twinned clinopyroxene, while slow cooling (slower than a few degrees per hour) of protopyroxene between $1000^{\circ} \mathrm{C}$ and $800^{\circ} \mathrm{C}$ produces ordered orthopyroxene (Brown and Smith. 1963; Smyth, 1974).

Reid et al. (1964) noted that the luminescence of disordered orthoenstatite in enstatite achondrites was weaker and the ratio of the intensity of blue to red luminescence was higher than for ordered orthoenstatite. Reid and Cohen (1967) suggested that disordered grains produced blue CL, while ordered grains from the same meteorite produced red $\mathrm{CI}$. The $\mathrm{x}$-ray powder diffraction suggests that one EH4 $\gamma$ (Abee), one EH5 $\beta$ (St. Mark), one Ellsy (St. Sauveur) and one EH5 $\delta$ (LEW88180) contains mixtures of disordered and ordered orthopyroxene with disordered orthopyroxene being dominant (Fig. 4). $A$ s noted above, these meteorites produce blue $\mathrm{Cl}$. On the other hand, the EL.5B and $\mathrm{E} I .6 \beta$ chondrites are composed predominantly of ordered orthoenstatite, and their enstatite produces magenta $\mathrm{Cl}$. Thus, we suspect that Reid and Cohen's (1967) suggestion that ordered orthoenstatite luminesces red and disordered orthoenstatite luminesces blue in aubrites 


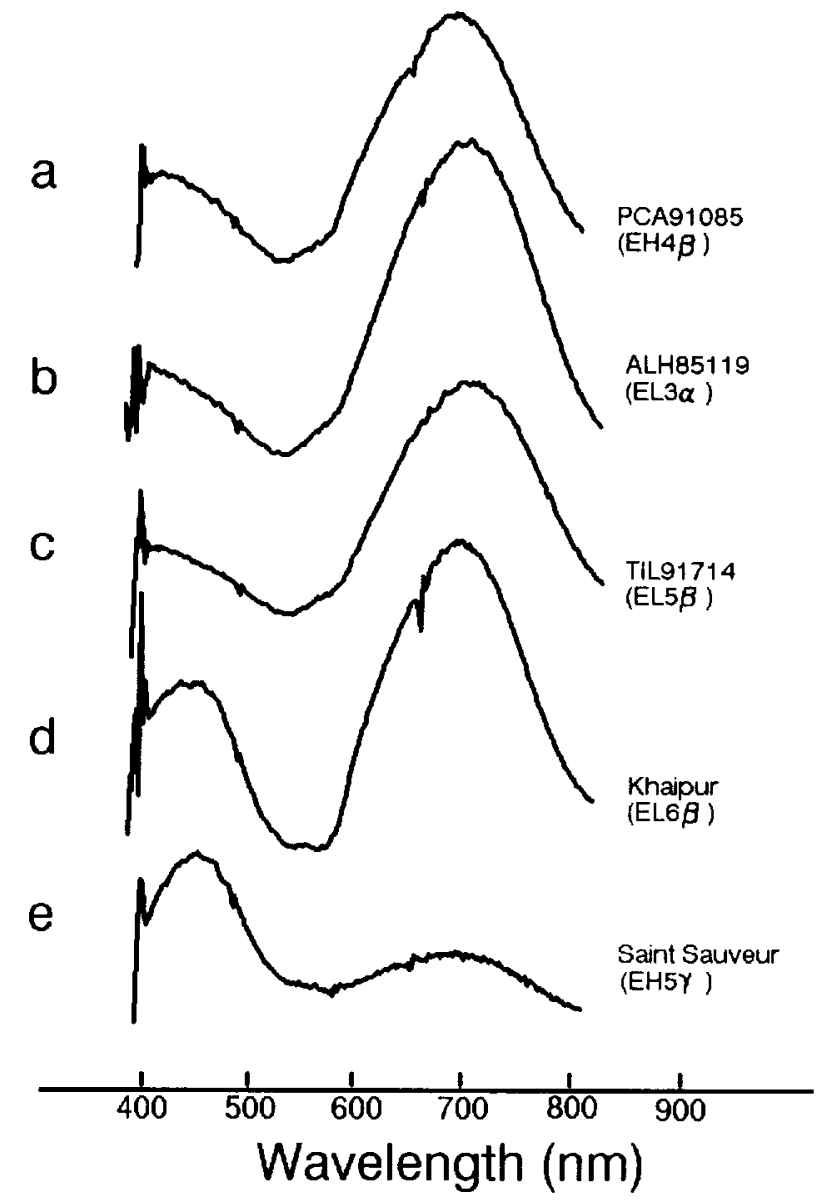

FIG. 2. Representative cathdoluminescence spectra of bulk samples of enstatite chondrite. Baselines have been displaced vertically for clarity. Little-metamorphosed chondrites of both the EH (a) and EL (b) classes have spectra with strong red $(-700 \mathrm{~nm})$ and weak blue $(-450 \mathrm{~nm}) \mathrm{CL}$ peaks. Metamorphosed EI chondrites ( $c$ and $d$ ) also have spectra with strong red peaks, but the bluc CL peaks can be of almost comparable intensity to the red CI, peak. Metamorphosed Ell chondrites have strong blue and weak red CL peaks. These spectra are consistent with CL. images in Plate 1.

is also true for the enstatite in the EL and EH chondrites. The present $\mathrm{x}$-ray diffraction data suggest that a major factor governing the $\mathrm{Cl}$, of metamorphosed enstatite chondrites is the structural state of the pyroxene.

We have begun a series of experiments in which we heat enstatite from meteorites in furnaces and observe the changes to their $C L$ and structure. To date, we have not been able to disorder

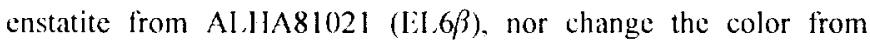
magenta to blue, but we did observe a change in the color of the $\mathrm{CL}$. from magenta to yellow-green, suggesting that the structure of the enstatite can affect its $\mathrm{Cl}$, (Schneider et al., 1995). The technique best suited to exploring the structural dependence of the $\mathrm{CL}$ of pyroxenes is arguably transmission electron microscopy (TEM). Unfortunately, such studies are very few. Buseck et al. (1982) summarized the major properties of enstatite with emphasis on TEM, and McCoy et al. (1995) reported data for llafegh 009. Ilafegh 009 is an unusual impact melt whose $C \mathrm{~L}$, we have not examined. It contains a disordered mixture of ortho- and clinopyroxene. Another promising method is single crystal XRD coupled with CI, spectra (I. Steele, pers. comm.).

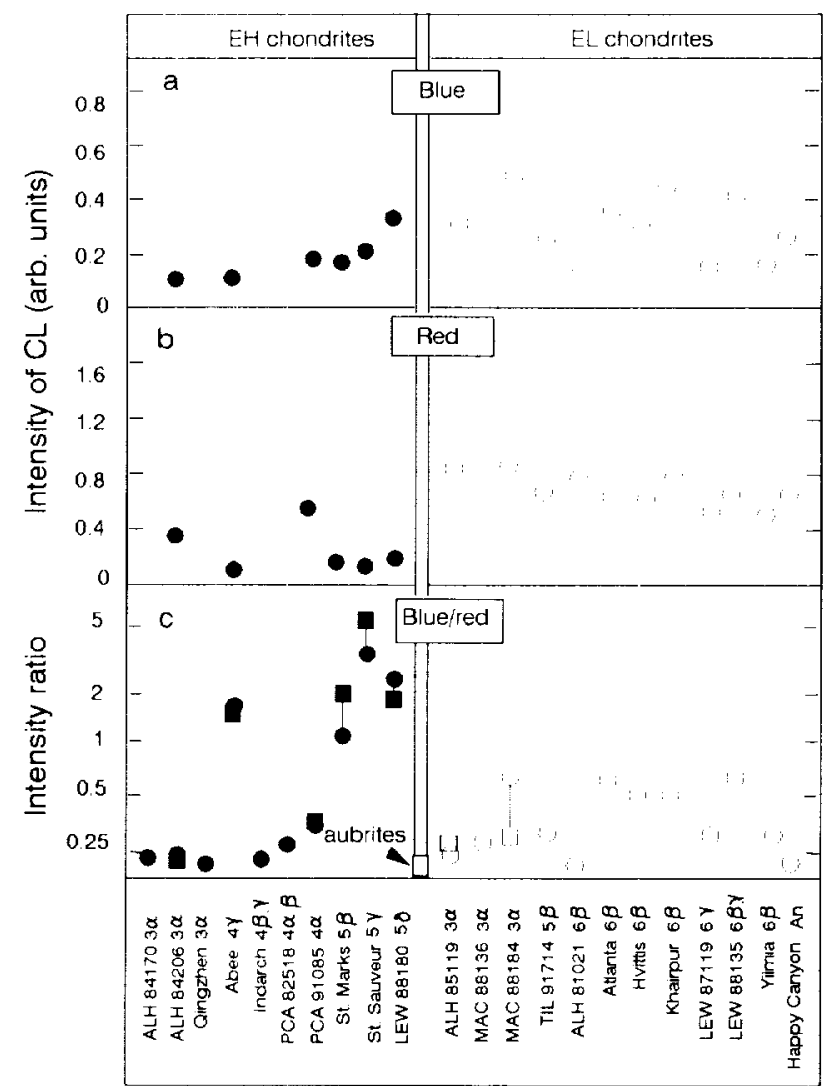

FIG. 3. Quantitative data for the bulk $\mathrm{Cl}$. properties of enstatite chondrites determined from $\mathrm{Cl}$. spectra similar to those of $\mathrm{Fig} .2$. (a) The intensity of the blue peak increases with textural and mineralogical type in the EH chondrites, but the IEL chondrites display no systematic trends. (b) The intensity of the red peak does not appear to vary systematically with textural and mineralogical type in either class but is a factor of -2 higher in the EI. chondrites. (c) The ratio of the intensity of blue and red peaks increases with type for the EH chondrites and is independent of type in the EL chondrites. It is higher for equilibrated EII chondrites than the other enstatito meteorites. Blue/red ratios obtained by point counting the $\mathrm{Cl}$ images are also shown as squares and connected to the spectral data by tie lines. Unless otherwise indicated, on all our figures lo experimental precisions are approximately twice the size of the symbols. Also shown is the range of blue to red spectral peak ratios measured for aubrites by Geake and Walker (1966).

\section{Induced Thermoluminescence Properties of Enstatite Chondrites}

Since the mineral producing the TL signal is undergoing structural and compositional changes as a result of metamorphism, it is worth considering whether the enstatite chondrites display major changes in ' 11 . sensitivity as a function of textural and mineralogical type like the ordinary chondrites. Variations in Tl. sensitivity resemble those of blue $\mathrm{Cl}$, as determined from the spectra, including an increase in the $\mathrm{Tl}$ sensitivity of the Ell chondrites with increasing petrologic type. However, the increase is fairly modest (about a factor of four), partly because the blue $T L$ is coming from both the "primary" blue enstatite of the sort observed in FH3 chondrites (Weisberg et al, 1994) and the "metamorphic" blue enstatite of the sort observed in EH6 8 chondrites (McKinley et al., 1984). The Ell chondrites plot at the lower end of the TL sensitivity range for $\mathrm{EL}$, chondrites, which is consistent with their difference in $\mathrm{Cl}$, intensity. The mosaics of $\mathrm{CL}$, from EI chondrites require longer photographic exposure times than those of the $1: \mathrm{L}$, chondrites. 


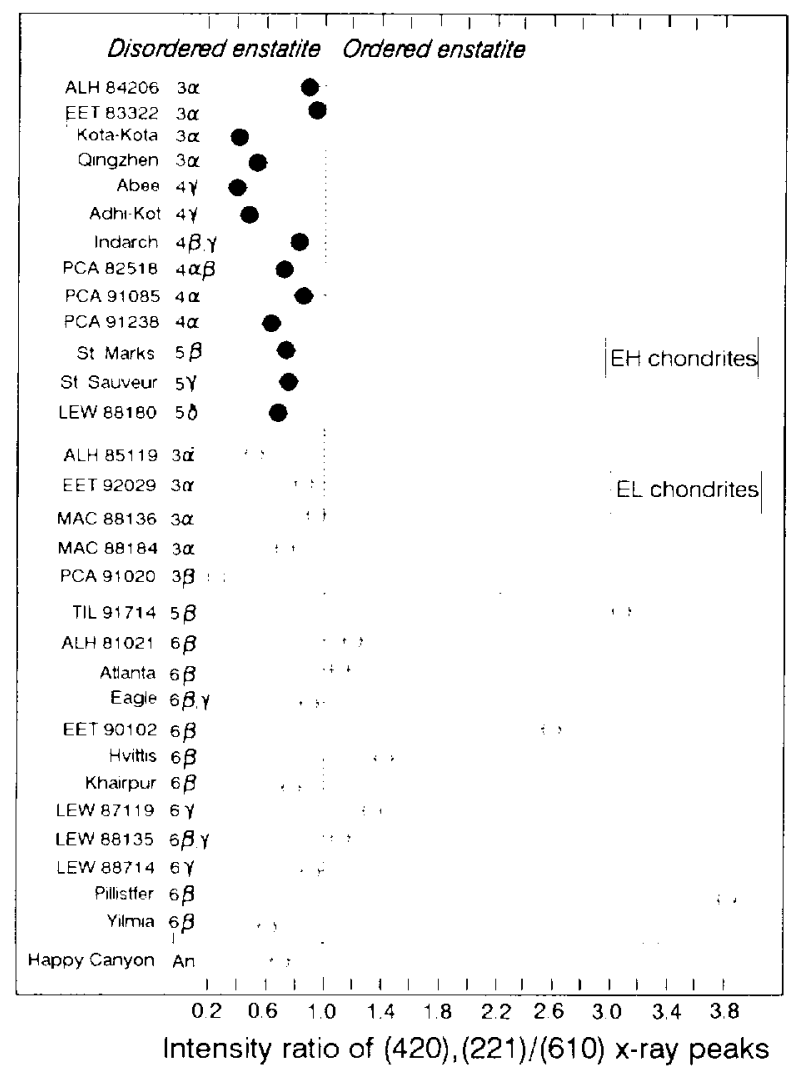

Fig. 4. The $x$-ray diffraction data for enstatite chondrites. According to Pollack and Ruble (1964), the relative intensity of the (420), (221) doublet and the (610) peak is a measure of the stacking order in the enstatite; the doublet peak is stronger than the singlet in ordered orthopyroxene but weaker for disordered orthopyroxenc. All of the FII chondrites and the EL $3 *$ chondrite appear to contain disordered enstatite, while eight of twelve IE 6 chondrites contain ordered enstatite.

The Eil. chondrites span almost a factor of 10 in their $\mathrm{TL}$ sensitivity. and the spread in TL sensitivity values displayed by l:L $6 \beta$ chondrites alone is comparable with the range shown by the I:L chondrites as a whole. Peak metamorphism alone, at least as reflected by the textural type, is clearly not governing TL, sensitivities. However, these I:L6 meteorites are primarily mineralogical type $\beta$, which suggests that their high TI, sensitivities are associated with ordered enstatite.

\section{The Thermal History and Origin of Enstatite Chondrites}

Probably the simplest explanation for the $\mathrm{CL}$ trends in Plate 1 is that while the enstatite is predominantly clinopyroxene in the EH3 $\alpha$ and $\mathrm{E}: 3,3$ chondrites, it is disordered orthopyroxene in the metamorphosed EHI chondrites and is ordered orthopyroxene in the metamorphosed EI. chondrites. This is the situation that is suggested, at least to some extent, by the optical and x-ray diffraction data in Table 1 and Fig. 4. With this as a working hypothesis, we will now summarize the available data

The EL5,6 Chondrites-The lack of chondrules in the EL6 chondrites, and the presence of only a few chondrule relics. indicates that they experienced very high peak metamorphic temperatures. Mason (1968) suggested a maximum equilibration temperature of $870^{\circ} \mathrm{C}$ based on the presence of quartz. Peak metamorphic temperatures for l:L $5.6 \beta$ chondrites lic between $600^{\circ} \mathrm{C}$ to $800^{\circ} \mathrm{C}$, which are bounded by the stability ficld of clinopyroxene

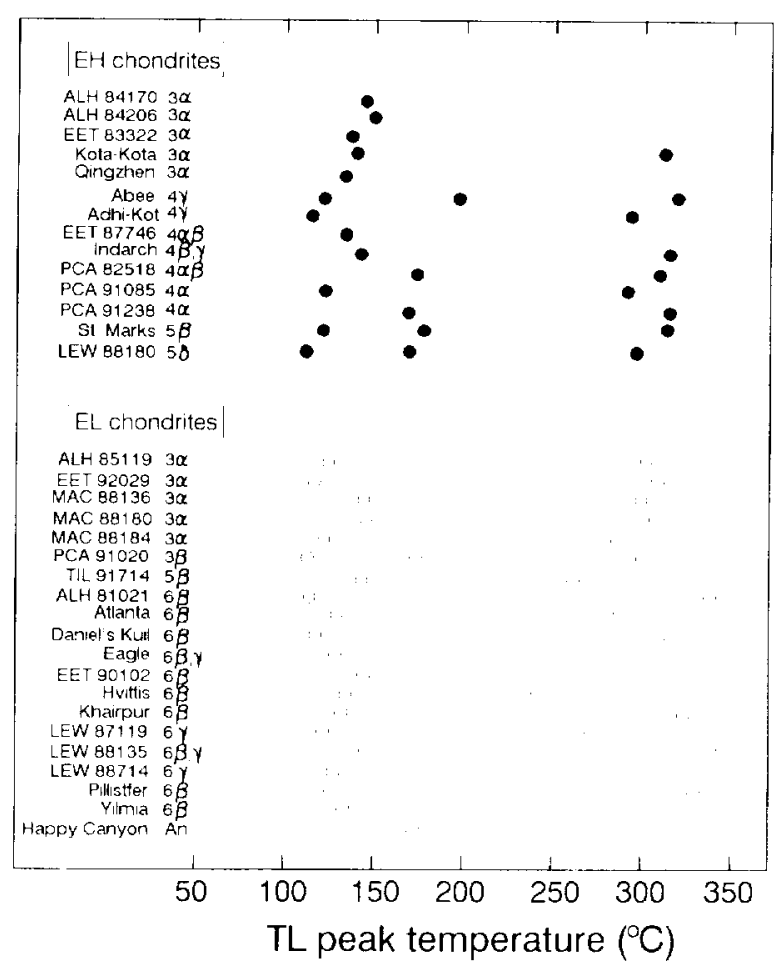

FIG. 5. Plot to compare the induced thermoluminescence peak temperatures of enstatite chondrites. Except for I:IBze chondrites, enstatite chondrites show peaks at $-140{ }^{\circ} \mathrm{C}$ and $-300{ }^{\circ} \mathrm{C}$ in the glow curve. In a few instances, the $\sim 140^{\circ} \mathrm{C}$ peak can be resolved into two peaks (at $-120^{\circ} \mathrm{C}$ and -170$)^{\circ} \mathrm{C}$ ). The EL6 $\beta$ chondrites show considerable scatter in the position of the high temperature peak.

$\left(600^{\circ} \mathrm{C}\right.$; Mason, 1968$)$ and the ordered structure of their pyroxene. The Schneider ef al. (1995) heating experiments indicate significant changes in $\mathrm{CL}$ after heating $>800{ }^{\circ} \mathrm{C}$. There are some exceptions to this generalization. Eagle, for instance, which was considered a post-metamorphism breccia with inclusions by Olsen et al. (1988). appears to contain disordered orthopyroxene and. therefore. equilibration temperatures $>800{ }^{\circ} \mathrm{C}$ (Fig. 4). Happy Canyon, which was considered an impact molt of El. composition by Mccoy et al. (1995), also contains disordered orthopyroxene. Despite this hightemperature episode, the low equilibration temperatures of the cubic sulfides for these two meteorites indicate that some systems closed at lower temperatures (Zhang et al. . 1992)

It seems that the transition between petrologic type 3 to 5.6 in El chondrites is not continuous, either because we have not yet recovered an EL 4 chondrite or because there was some mechanical process to separate these E. 5,6 chondrites from original lil.3 chondrites before they underwent high peak temperatures that destroyed chondrules. Experience shows that it is probably due to the lack of complete sampling of the enstatite meteorite classes.

The EH5,6 chondrites-The EJI5,6 chondrites contain a mixture of clino, ordered and disordered orthopyroxene (Table 1). In fact, based on their textures, the homogeneity of their mineral chemistry and the presence of only $-10 \%$ enstatite grains with magenta color, it is clear that these meteorites underwent prolonged metamorphism at high temperatures with the equilibration temperatures for a number of mineral systems being $\sim 900^{\circ} \mathrm{C}$ ( (Zhang et al., 1992). We suggest that their equilibration temperatures (as opposed to their peak-metamorphic temperatures) are higher than those of 


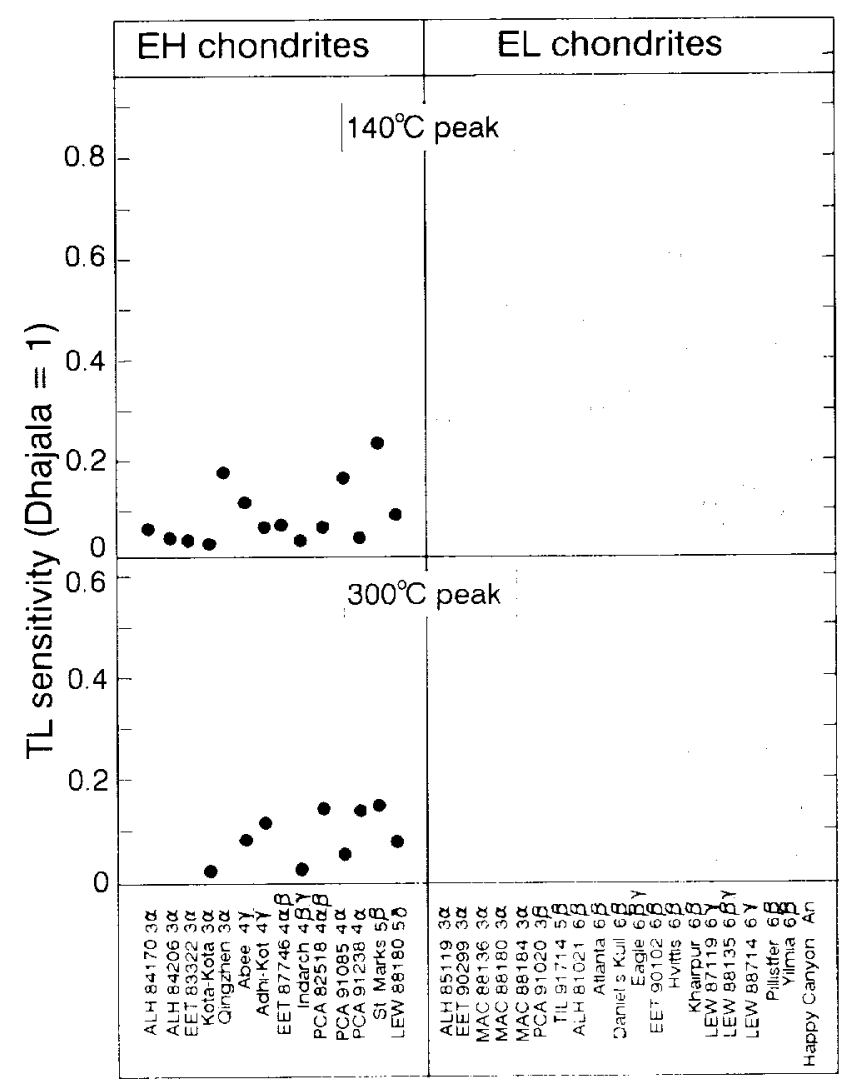

FIG. 6. Plot comparing the thermoluminescence sensitivities of enstatite chondrites. The $\sim 140^{\circ} \mathrm{C}$ and the $-300{ }^{\circ} \mathrm{C}$ peaks behave similarly, suggesting that they are caused by the same luminescent minerals and activators. Since our TL apparatus is biased towards blue wave lengths, the variations in TL sensitivity shown by enstatite chondrites resemble those of the blue CL intensity.

EL5,6 chondrites $\left(-800{ }^{\circ} \mathrm{C}\right)$ in order to produce the disordered structure. At the end of this metamorphic event or subsequent to it, most of these meteorites underwent rapid cooling (faster than a few degrees per hour) to produce the observed mixture of enstatite structural states and metal structures observed in Abee (Herndon and Rudee, 1978). This scenario is consistent with the proposed higher shock levels of $\mathrm{EH} 5,6$ chondrites compared with EL,5,6 chondrites (Rubin and Scott, 1995) because rapid cooling following shock would favor disordered structures. However, interpretation of shock effects must be considered tentative until the effects of shock on the various pyroxene structures are considered.

The E3 Chondrites-In type 3 chondrites, the clinopyroxene has either blue or red $\mathrm{CL}$ depending on transition metal contents: apparently, CL color is not uniquely identified with this structure. Weisberg et al. (1994) proposed that chemical processes in the nebula resulted in the compositional diversity (and thereby $\mathrm{Cl}$. colors) of the enstatite in type $3 a$ chondrites and that red $\mathrm{CL}$ enstatite grains are solid-state reduction products while blue CL enstatite grains are condensates from the nebula. Ilsu and Crozaz. (1994) argued that both types of enstatite were produced from melts, based on their similar REE patterns. Previous studies suggested that clinopyroxene produced by the fast cooling of protopyroxene is usually twinned while clinopyroxene produced by shearing stress from orthopyroxene is not usually twinned (Brown and Smith, 1963; Smyth. 1974). The higher abundances of twinned clino-

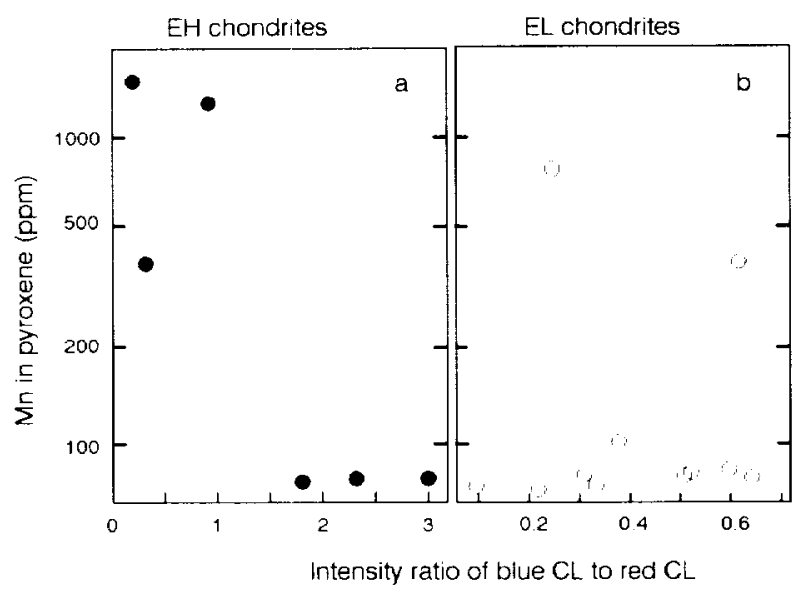

Fig. 7. Plot to compare the $\mathrm{Mn}$ content in pyroxene in enstatite chondrites with the intensity ratio of blue ( $\mathrm{L}$. to red $\mathrm{CL}$ obtained from the spectra. (a) III chondrites show a decrease in the $\mathrm{Mn}$ content of the enstatite with increasing blue $\mathrm{CI}$, to red $\mathrm{CI}$, ratio. (b) $\mathrm{EI}$, chondrites display no obvious trend.

pyroxene in 13 chondrites compared to $1: 115,6$ chondrites reflects the difference in metamorphic history.

Comparison Between EH and EL Parent Bodies-Several authors have suggested that the EH and $\mathrm{EL}$, chondrites represent different parent bodies with the arguments centering on differences in breccia types and abundances, bulk compositions (Keil, 1989) and cosmic-exposure age distributions (Crabb and Anders, 1981). The EL and EII chondrites also experienced different thermal histories, and there is, thus, a different distribution of enstatite chondrites over the textural and mineralogical types (Jig. 8). Most EII chondrites are low textural and low mineralogical types, whereas most EL chondrites are high mineralogical and high textural types, which suggests that the EI, chondrites experienced a prolonged period of low-temperature metamorphism that the EII chondrites escaped. This different thermal history took place after peak metamorphism and possibly involved breakup of the lill and EL parent bodies. Virtually all the equilibrated Ell chondrites and a few $\mathrm{EL}$, chondrites were involved in an event that resulted in rapid cooling. The fragmental breccias among the LII chondrites (e g., Abee and St. Sauveur) may be evidence of this event. The environment is a matter of speculation. Zhang et al. (1995) suggested that differences in thermal blanketing in a regolith might have been responsible.

Aubrites-The aubrites have thermal histories that are more like l:II chondrites than the EL, chondrites. The aubrites experienced a violent breakup, which resulted in heating and rapid cooling. Aubrites contain large enstatite crystals and a mixture of ordered and disordered orthoenstatite. It is possible that the impact and rapid cooling event was associated with the event(s) that produced the numerous breccias observed in this meteorite group (Keil. 1989).

\section{CONCLUSIONS}

The CI, properties of enstatite in un- or little-metamorphosed $\mathrm{EH}$ and $\mathrm{El}$. chondrites are similar; enstatites with high 1ransition metal contents have red $\mathrm{Cl}$, while relatively pure enstatites have blue (L. Rare enstatites with $>5$ wt \% $\mathrm{FeO}$ have no (L. Metamorphosed lill chondrites display predominantly blue CL, while metamorphosed EI, chondrites display magenta $\mathrm{CL}$, whose spectra contain blue and red peaks of approximately equal intensity. 


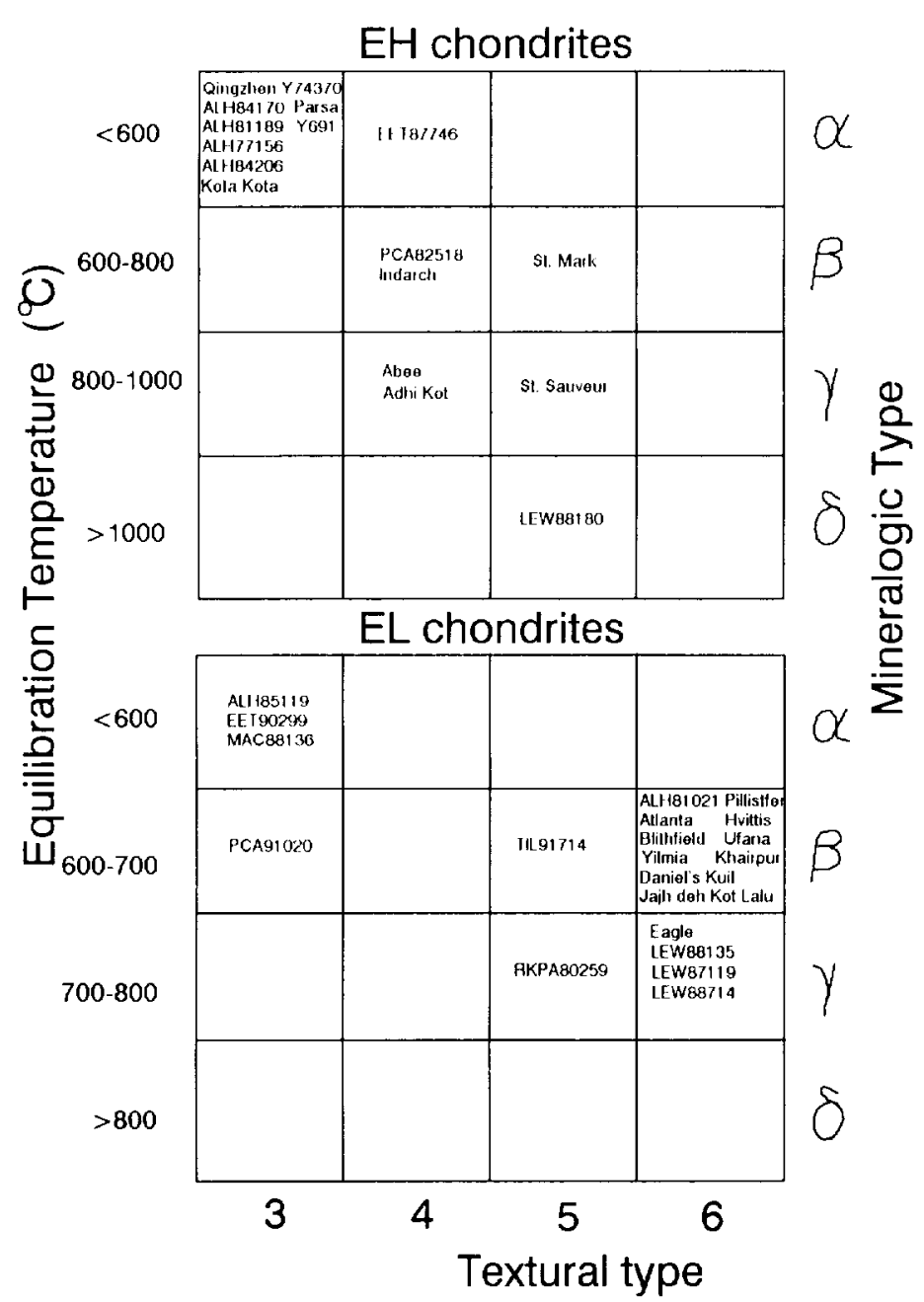

FIG. 8. Distribution of enstatite chondrites over mineralogic $(\alpha-\delta)$ and textural $(3-$ 6) types with suggested equilibration temperatures that are based on the pyroxene struclure.

The TL sensitivities of EH chondrites correlate with the intensity of the blue $\mathrm{Cl}$, and correlate very weakly with textural type. The $\mathrm{TL}$. sensitivities of $\mathrm{EL}$ chondrites show a wide range, being generally higher than those of EH chondrites, and show no evidence of correlating with textural type.

The diverse $\mathrm{Cl}$, properties of enstatite in unmetamorphosed enstatite chondrites are readily understood in terms of minor- and trace-element composition, but this is not the case for metamor-

TABLE 3. Summary of cathodoluminescence color, composition and structure of enstatite in enstatite chondrites

\begin{tabular}{lcl}
\hline CL color & Mn $(\mathrm{ppm})$ & Structure* \\
\hline Red & $>350$ & Cpx and opx \\
Magenta & $<350$ & Ordered opx \\
Yellow-green & $<350$ & $\begin{array}{l}\text { Disordered opx } \\
\text { with twinned cpx }\end{array}$ \\
Bluc & $<350$ & $\begin{array}{l}\text { Disordered opx } \\
\text { with untwinned cpx }\end{array}$ \\
\hline
\end{tabular}

* "cpx" and "opx" refers to clinopyroxene and orthopyroxene, respectively. phosed enstatite chondrites. The $x$-ray diffraction measurements and optical microscopy suggest that unmetamorphosed enstatite chondrites of both classes contain clinopyroxene (with small amounts of disordered orthopyroxene), but metamorphosed EH chondrites contain predominantly disordered orthopyroxene and metamorphosed EL chondrites contain predominantly ordered orthopyroxene. These conclusions are summarized in Table 3.

The differences in the structural form of the enstatite in metamorphosed EH and EL chondrites indicate major differences in the thermal history of the two classes following peak metamorphism. The EH chondrites cooled relatively quickly. but the EL chondrites were heated for a prolonged period in the stability field of orthopy roxene $\left(600{ }^{\circ} \mathrm{C}-800^{\circ} \mathrm{C}\right)$.

Acknowledgments-We are grateful to the Meteorite Working Group of NASANSF, I. Casanova (Field Museum of Natural History. Chicago, Illinois), R. Hutchison (The Natural Ilistory Museum, Lindon), G. Kurat (Naturhistorisches Museum Wien, Vienna), M. Primz (American Museum of Natural History, New York), L. S. Schramm (National Muscum of Natural History, Smithsonian Institution, Washington, D.C.), L. Schultz (Max-Planck Institut für Chemie, Mainz) and B. Zanda (Muséum d'Histoire Naturelle. Paris) for supplying samples; especially to Walter Manger and Ronald Konig (University of Arkansas, Geology Department) for their continued generous loan of the cathodoluminescence and $\mathrm{x}$-ray diffaction equipment; and to Gordon McKay and Vincent Yang for access to and help with the JSC electron microprobe analysis. Wc also especially appreciate useful reviews by Katherina Lodders and Ian Stecle. This work was supported by a grant from NASA (NAGW 3519) while DS was supported by an NSF REU award.

Editorial handling: K. Keil

\section{REFERENCES}

ANGel R. H., Chotpelas A. And Ross N. L. (1992) Stability of highdensity clinoenstatite at upper-mantle pressures. Nature $\mathbf{3 4 8}$, $322-324$.

Benoit P. H., Sears H. AND Sears D W G (1991) Thermoluminescence survey of 12 meteorites collected by the European 1988 Antarctic meteorite expedition to Allan llils and the importance of acid washing for thermoluminescence sensitivity measurements. Meteoritics 26, 157-160.

BROWN W. AND SMITH J. V. (1963) High-temperature x-ray studies on the polymorphism of $\mathrm{MgSiO}_{3}$. Zeit. Krist. Bd. 118, 186-212.

BUSECK P. R. AND HOLDSWORTH E. F. (1972) Mineralogy and petrology of the Yilmia enstatite chondrite. Meteoritics 7, 429-447.

BusECK P. R., NORD G. I. AND VEBI.EN D. R. (1982) Subsolidus phenomena in pyroxenes. Rev. Mineral. 60, $117-211$.

Cassidy W., Harvey R., Schutt J., Delisle G. AND Yanal K. (1992) The meteorite collection sites of Antarctica. Meteoritics 27,490-525.

CHANG Y., BENOIT P. AND SEARS D. W. G. (1992) Bulk compositional confirmation of the first EL3 chondrite and some implications (abstract). Lunar Planet. Sci. 23, 217-218

CRABB J. AND ANDERS E. (1981) Noble gases in E-chondrices. Geochim. Cosmochim Acta 45, 2443-2464.

DEHART J. M. AND LOFGREN G. E. (1994) The occurrence of blue luminescencing enstatite in E3 and E4 chondrites (abstract). Limor Planet. Sci. 25, 319-320.

DeHART J. M. AND Lofgren G. E. (1995) Formation and metamorphism in enstatite chondrites (abstract). Lunar Planet Sci. 26, 325-326.

DERHAM C. J. AND GEAKE J. E. (1964) Luminescence of meteorites. Nature 201, 62-63.

Derham C. J., Geake J. E. AND Walker G. (1964) Luminescence of enstatite achondrite meteorites. Nature 203,134-136.

Fogel R. A., Hess P. W. and Rutherford M. C. (1989) Intensive parameters of enstatite chondrite metamorphism. Geochim. (osmochim. Acta 53, 2735-2746.

GEAKE J. E. AND WALKER G. (1966) The luminescence spectra of meteorites. Geochim. Cosmochim. Acta 30, 929-937.

GEAKE J. E. AND WALKER G. (1967) laboratory investigations of meteorite luminescence. Proc. Royal Soc. A 296. 337-346.

GRÖGlER N. AND L.IENER A. (1968) Cathodoluminescence and thermoluminescence observations of aubrites. In Thermolmminescence of 
Geological Materials (ed. D. J. McDougall), pp. 569-578. Academic Press. New York.

(GUIMON R. K., SYMES S. J. K., BENOIT P. H. AND SEARS D. W. G. (1995) Chemical and physical studies of type 3 meteorites XII: Metamorphic history of $\mathrm{CV}$ chondrites and their components. Meteoritics 30, 704714.

IIERNDON J. M. AND RUDFF M. L. (1978) Thermal history of the Abee enstatite chondrite. Earth Planet. Sci. Lett 41, 101-106.

IISU W. AND CROZAZ G. (1994) On the formation of enstatite in unequilibrated enstatite chondrites (abstract). Lunar Planet. Sci. 25, 571-572.

KAILLMEYN G. W. AND WASSON J. T. (1986) Compositions of enstatite (EH3, EH4,5 and EL_6) chondrites: Implications regarding their formation. Geochim. Cosmochim. Acta 46, 597-608.

KANZAKI M. (1991) Ortho/clinoenstatite transition. Phys. (hem. Min. 17, $726-730$

KEII. K. (1968) Mineralogical and chemical relationship among enstatite chondrites. J. Geophys Res. 73, 6945-6977.

KEIL. K. (1989) Fnstatite meteorites and their parent bodies. Meteoritics 24, 195-208.

LARIMLR J. W. AND BUSICK P. R. (1968) Fquilibration temperatures in enstatite chondrites. (jeochim. (osmochim. Acta 38, 471-477.

Leitch C. A. AND SMITH J. V. (1982) Petrography, mineral chemistry and origin of Type I enstatite chondrites. Geochim. Cosmochim. Acka 46, $2083-2097$

l.N Y. T., NIAL H. J., IUINDIRRG 1.. L. AND IL. GoRESY A. (1991) MAC88136-the first EI.3 chondrite (abstract). Lunar Planet Sci. 22. $8 ! 1-812$.

L.OFGREN G. AND DEHART J. M. (1992a) Dynamic crystallization studies of enstatite chondrite chondrules: Cathodoluminescence properties of enstatite (abstract). Lunar Plonet $S_{c i}$ 23, 799-800

LOFGREN G. AND DeHART J. M. (1992b) Relict enstatite and olivine in porphyritic chondrules from enstatite chondrites formed by partial melting of precursor material (abstract). Lunar Planet. $S_{c i}$. 23, 801802 .

I.OFGREN G. AND DEHART J. M. (1993) The occurrence of blue luminescing cnstatite in E3 ad E4 chondrites (abstract). Lunar Planet Sci. 25.319320 .

LusBY D., Scort E. R. D. AND Klall. K. (1987) Ubiquitous high FeOsilicates in enstatite chondrites. Proc Lunar Planet. Sci. Conf 17th, J. Geophys. Re's. 92, E679-E695

MARSHALL D. J. (1988) ('uthodoluminescence of Geological Materials. Allen and Unwin. Winchester. Massachusettes. $146 \mathrm{pp}$.

MASON B. (1966) The enstatite chondrites. Geochim. Cosmochim. Acta 30, $25-39$

MAson B. (1968) Pyroxenes in meteorites. Lithos 1, 1-11

MASON B. (1990) In Antarctic Meteorite Newsletter 13(3). NASA Johnson Space Center, Houston, Texas

MCCOY T. J., KEIL K., BOGARD D. D., GaRRISON D. H., CASANOVA I., I INDSTROM M. M., BRLAARIEY A. J., KEHM K., NICHOLIS R. H. AND HOHENBERG C. M. (1995). Origin and history of impact-melt rocks of enstatite chondrite parentage (ieochim. Cosmochim. Acta 59, 161175.

MCKinLEY S. G. EDWARDS R. D. S. AND KEIL K. (1984) Composition and origin of enstatite in F chondrites. J. Geophys. Res. 89, B567-B572

OLSEN E. J., BUNCII T. F., JAROSEWICH E., NOONAN E. F. AND HUSS G (1977) Happy Canyon: A new type of enstatite chondrite. Meteoritics $12,109-123$.

OLSEN E. J., Huss (j. I. MND Jakostiwich E. (1988) The Eagle, Nebraska, enstatite chondrite ( $\Gamma: L$ 6) (ahstract) Meteoritics 23, 379-380.

PACALO R. E. G. AND GASPARIK T. (1990) Reversals of the orthoenstatiteclimenstatite transition at high pressure and high temperatures. I. Geophys. Res. 95, $15853-15858$

POLLACK S. S. (1966) Disordered orthopyroxene in meteorites, Amer. Min. $51,1722-1726$

POLLACK S. S. (1968) Disordered pyroxene in chondrites. Genchim. (osmochim Acta 32, 1209-1217.

POLLACKS. S. ANI) RIBBIF W. M. (1964) X-Ray identification of ordered and disordered ortho-enstatite. Amer. Min. 49, 983-992.

REID A M AND COHIN A. J. (1967) Some characteristics of enstatite from enstatite achondrites. Geochim. ('osmochim Acra 31, 661-672
REID A. M., BUNCH T. E., COHEN A. J. AND POLLACK S. S. (1964) Luminescence of orthopyroxene. Nature 204, 1292-1293.

RUBBIN A. E. AND SCOTT E. R. D. (1995) Shock metamorphism of enstatite chondrites (abstract) Lunar Planet. Sci. 26, 1197-1198.

SChNeIder D. M., Zilang Y., SEars D. W. G. AND BinoIT P. II. (1995) Differences in the metamorphic history of high petrologic type EH and FL chondrites and their luminesecnce properties (abstract). lunar Planet. Sci. 26, 1245-1246

SCORE R. AND LINISTROM M. M. (1990) Guide to the U. S. collection of Antarctic metcorites 1976-1988. In Antarctic Meteorite Newsletter 13 (1) NASA Johnson Space Center, Houston, Texas.

SEARS D. W. (3. AND WEEKS K. S. (1984) First known III5 chondriteevidence for dual genetic sequence for enstatite chondrites. Nature $308,257-259$

Sfars D. W. Grossman J. N. MFlchitr C. L.. Ross L. M. and Mills A A. (1980) Measuring the metamorphic history of unequilibrated ordinary chondrites. Nature 287, 791-795.

SEARS D. W. KAll EMEYN G. W AND WASSON I T (1982) The chemical classification of chondrites II: The enstatite chondrites. Geochim Cosmochim Acta 46, 597-608

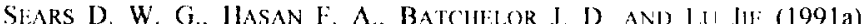
Chemical and physical studies of type 3 chondrites XI: metamorphism, pairing and brecciation of ordinary chondrites. Proc. Lunar Planet. Sci. Conf. 21st, 493-512.

SEARS D. W. (i., LU J., Kl:CK B. D. AND BATCHELOR J. D. (199lb) Metamorphism of $\mathrm{CO}$ and $\mathrm{CO}$-like chondrites and comparisons with type 3 ordinary chondrites. Proc. NIPR Symp. Anturct. Meteor. 4th, $1745-1805$

SKINNFR B J. AND LUCE: F. D. (1971) Solid solutions of the type (Ca, Mg. $\mathrm{Mn}, \mathrm{Fe}) \mathrm{S}$ and their use as geothermometers for the enstatite clondrites Amer. Min. 56, 1269-1295.

SKOGBY II. (1992) Order-disorder kinetics in orthopyroxenes of ophiolite origin. Contrib. Mineral. Petrol. 109, 471-478

SMYTI J. R. (1974) Experimental study on the polymorphism of enstatite Amer Min. 59, 345-352.

STEFLE I. M. (1989) Mineralogy of metcorites revealed by cathodoluminescence. In Spectroscopic Characterization of Minerals and their Surfaces (eds. L. M. Coyne, S. W. S. McKeever and D. I. Blake), pp. 150-164. ACS Symp ser 415, Washington, D.C

VAN SCHMUS W. R. AND WOOD J. A. (1967) A chemical-mineralogic classification for the chondritic meteorites. Geochim. Cosmochim. Acte $31,747-765$

WANG D. AND XIE X. (1981) Preliminary investigation of mineralogy, petrology and chemical composition of Qingzhen enstatite chondrite. Geochemistry 1, 69-81.

WATTERS T. R. AND PRINZ M (1979) Aubrites: Their origin and relationship to enstatite chondrites. Proc Lunar Planet. Sci. (onf. 10th, 10731093.

Waychinas G. A. (1988) luminescence, X-ray emission and new spectroscopies. Rev Mineral 18, 639-698.

WEEKS K. S. AND SEARS D. W. (3. (1985) Chemical and physical studies of type 3 chondrites-V: The enstatite chondrites. Geochim Cosmochim Acta 49, $1525-1536$

Weisberg M. K., PRINZ M. AND Fogil R. A. (1994) The evolution of enstatite and chondrules in unequilibrated enstatite chondrites: Evidence from iron-rich pyroxene. Meteoritics 29, 362-373.

ZIMANG Y., BENOIT P. II AND SEARS D. W. (i. (1992) The thermal history of enstatite chondrites (abstract). Meleoritics 27, 310-311

Zhang Y., BenotT P. II and Sears D. W. (j. (1993) l.I:W88180. LEW 87119 and ALI185119: New EHIG, I:1.7 and I:L.4 enstatite chondrites (abstract). Meteoritics $\mathbf{2 8}, 468$.

ZHANG Y., BENOIT P. ANI) SBARS D. W. (i. (1994a) The unique thermal history of EL chondrites and a new means of classifying equilibrated enstatite chondrites (abstract). Lanar Planet. Sci. 25, 1547-1548

ZHANG Y., BENOIT P. AND SEARS D. W. G. (1994b) The complex thermal history of enstatite chondrites (abstract). Lunar Plonet S. Si. 25, 1545 1546 .

Zhang Y., BENOIT P. AND SEARS D. W. G. (1995) The classification and complex thermal history of the enstatite chondrites. If (ieophys Res. Planets 100,9417-9438. 